\title{
The new clinical application of bilateral- contralateral cervix clamp in postpartum hemorrhage: a retrospective cohort study
}

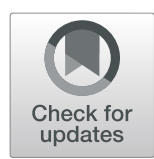

\author{
Qianwen Zhang ${ }^{1,2}$, Tao $\mathrm{Li}^{1,2}, \mathrm{Yu} \mathrm{Xu^{1,2 } \text { and Yayi Hu}}{ }^{1,2^{*}}$
}

\begin{abstract}
Background: To assess the efficacy and safety of bilateral-contralateral cervix clamp firstly applied in postpartum hemorrhage caused by uterine tony of lower segment.

Methods: Totally 47 pregnant women with postpartum hemorrhage secondary to lower uterine segment atony in vaginal delivery or after caesarean delivery were included from March 1, 2020 to May 31, 2020. According to patient's informed consent, 22 women accepted cervical clamp to treat and 25 only used uterotonics in control group.

Then hemostatic efficacy and safety of bilateral-contralateral cervix clamp were assessed by retrospective analysis.

Results: It was found that mean blood loss in clamp group was much less during vaginal delivery $(656.2 \pm 72.79 \mathrm{~g}$ vs $811.8 \pm 86.07 \mathrm{~g}, p=0.001)$ or after caesarean delivery $(42.8 \pm 6.60 \mathrm{~g}$ vs $126.3 \pm 86.97 \mathrm{~g}, p=0.007)$, and incidence of uterotonic repeated usage $(81.8 \%$ vs $36,18.2 \%$ vs $64 \%, p=0.001)$ or side effect $(18.2 \%$ vs $48.0 \%, p=0.031)$ appeared less than control group, but there was no statistical differences on hospital stay $(4.1 \pm 1.57$ days vs $3.8 \pm$ 1.61 days, $p=0.535)$, hemoglobin (119 $\pm 4.10 \mathrm{~g}$ vs $121.4 \pm 4.19 \mathrm{~g}, p=0.058)$, blood transfusion $(9.1 \%$ vs $12 \%, p=0.746)$, surgical procedures ( $4.5 \%$ vs $4.0 \%, p=0.93)$, also no clamp complications occurred.
\end{abstract}

Conclusions: The bilateral-contralateral cervix clamp was effective and safe, this new technique could be a complementary treatment for postpartum hemorrhage.

Keywords: Postpartum hemorrhage, Uterine atony, Uterotonic, Cervix clamp

\section{Background}

Postpartum hemorrhage (PPH) is commonly defined as a blood loss within $24 \mathrm{~h}$ more than $500 \mathrm{ml}$ at vaginal delivery or $1000 \mathrm{ml}$ at cesarean delivery, it was mainly secondary to uterine atony, including atony of lower uterine segment $[1,2]$. PPH has always been the leading cause of maternal death globally, almost resulted in $34 \%$ of 275,000 maternal deaths worldwide in 2015, and as high as $17.62 \%$ in Chinese maternal deaths according to the National

\footnotetext{
*Correspondence: yayihu@sina.com; yayihuwestchina@163.com

'Department of Obstetrics and Gynecology, West China Second University Hospital, Sichuan University, Chengdu, Sichuan, China

${ }^{2}$ Key Laboratory of Birth Defects and Related Diseases of Women and

Children, Sichuan University, Ministry of Education, Chengdu, Sichuan, China
}

Maternal and Child Health Annual Report of China in 2018 [3-5]. The World Health Organization (WHO) updated recommendation for preventing $\mathrm{PPH}$ is $10 \mathrm{IU}$ of oxytocin for all births, and uterotonics such as carbetocin, ergometrine and misoprostol could help uterine contraction effectively [6, 7]. However, oxytocin desensitization may decrease effectiveness, and uterotonics also has drug contraindications and side effect such as water intoxication, nausea, vomiting, and increased blood pressure $[8$, 9]. Furthermore, lacking uterotonics, blood products or interventional therapy could extremely increase risk of maternal deaths in low income countries with limited resources [10]. As to PPH during vaginal delivery or after

(c) The Author(s). 2021 Open Access This article is licensed under a Creative Commons Attribution 4.0 International License, which permits use, sharing, adaptation, distribution and reproduction in any medium or format, as long as you give appropriate credit to the original author(s) and the source, provide a link to the Creative Commons licence, and indicate if changes were made. The images or other third party material in this article are included in the article's Creative Commons licence, unless indicated otherwise in a credit line to the material. If material is not included in the article's Creative Commons licence and your intended use is not permitted by statutory regulation or exceeds the permitted use, you will need to obtain permission directly from the copyright holder. To view a copy of this licence, visit http://creativecommons.org/licenses/by/4.0/ The Creative Commons Public Domain Dedication waiver (http://creativecommons.org/publicdomain/zero/1.0/) applies to the data made available in this article, unless otherwise stated in a credit line to the data. 
vaginal/cesarean delivery, intrauterine Bakri balloon, urgent UAE or laparotomy would be further treatment if uterotonics didn't work, so it was important to find another conservative treatment. Given all this, the bilateralcontralateral cervix clamp was firstly introduced and applied in postpartum hemorrhage, aiming to confirm its efficacy and safety against uterotonics.

\section{Methods}

The study began with approved by the Ethics Committee in West China Second University Hospital of Sichuan University (ethics number:2020068). From March 1, 2020 to May 31, 2020, there were total 69 pregnant women with PPH of 1190 delivery quantity caused by uterine atony. Among them, 22 women were excluded because 9 $\mathrm{PPH}$ occurred during cesarean section, 8 refused to participate and others had abnormal coagulation or severe cervical laceration/erosion. Finally 27 cases of PPH during vaginal delivery and 20 after vaginal/cesarean delivery were included. According to the informed consent principle, 22 women agreed to accept cervical clamp and 25 unwilling participants in control group used uterotonics (Fig. 1). Except routine Oxytocin, Carbetocin, Ergometrine or Hemabate was commonly used in our hospital, and further surgical procedures like intrauterine Bakri balloon, urgent UAE, laparotomy could be next treatment if needed. To increase comparability, two obstetricians finished the clamp, and three experienced midlives or obstetricians together adopted quantitative measurement to estimate blood loss, confirmed uterine atony by transvaginal uterine massage, then the nursing or epidural anesthesia was the same. The main outcomes were blood loss, uterotonic repeated usage and side effect, clamp complications, surgical procedures and hospital stay etc.
This bilateral-contralateral cervix clamp would be performed as first uterotonic failed or women with uterotonic contraindications. The operating steps as follows, emptying bladder after routine disinfection, vaginal speculum or tractors to expose cervix; The operator held 12 o'clock with cervical forceps, and two elbow-toothless sponge forceps to clamp front and back lip of cervix together at 3 and 9 o'clock contralaterally. The clamp depth should be $0.5 \mathrm{~cm}$ below the bladder reflex, and maintain $15 \mathrm{~min}$ with moderate closure degree. All those mentioned above contributed to blocking blood supply for lower uterine segment and stimulating endogenous oxytocin released better, preventing bladder and cervix injury as well. It was also necessary to keep cervical canal unobstructed, which was easy to observe active bleeding, timely judge hemostatic effect and if next procedure must be urgently applied or not (Fig. 2).

\section{Statistical analysis}

Sample size calculations were performed using PASS 2011 software (NCSS, LLC, Kaysville, UT, USA). As previously described by Jiang [11], 44 women were performed BABC (Bilateral Cervix Apex Clamping) to confirm it could reduce the incidence of severe PPH and UAE. Therefore, we included 47 women in the trial, assuming a statistical difference between two groups. All statistical data were analyzed by using SPSS version 22.0 (IBM, Armonk, NY, USA), The continuous variables were presented as mean \pm standard deviation $(\mathrm{SD})$, whereas categorical variables were expressed as frequency, $\mathrm{n}(\%)$, then a $\mathrm{t}$-test or chisquare test might be used to compare clinical characteristics between groups. A value for $\mathrm{p}<0.05$ was considered statistically significant.

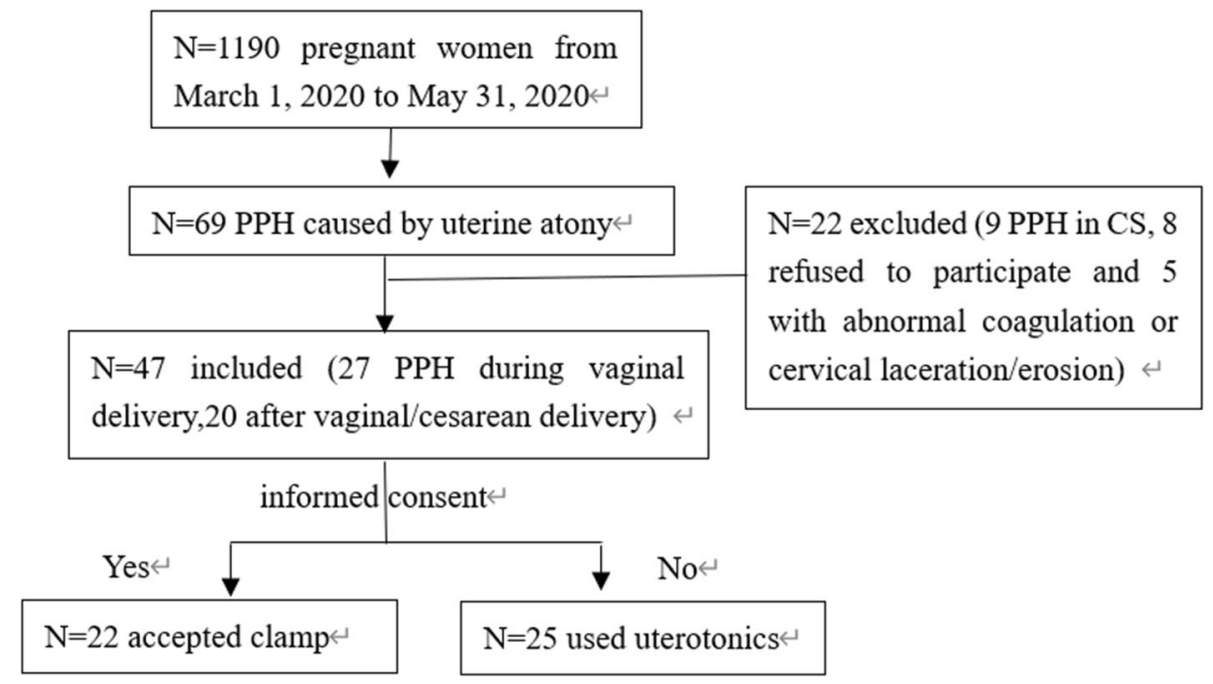

Fig. 1 Flowchart showing the number of included and excluded subjects 

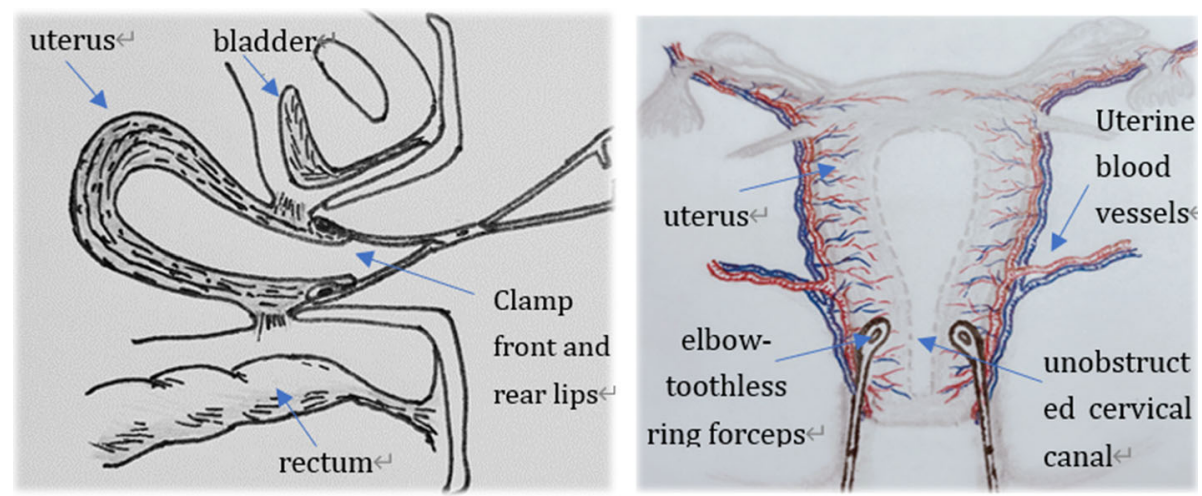

Fig. 2 The image decapitated is our own and shows the operation points of the bilateral-contralateral cervix clamp

\section{Results}

Retrospective analysis of clinical data found no statistical differences on maternal characteristics between two groups, including some important factors like scarred uterus and uterotonic contraindications such as gestational hypertension, preeclampsia, heart disease, glaucoma, bronchial asthma (Table 1). Among 27 women during vaginal delivery, the intrapartum blood loss in clamp group was less than control group $(656.2 \pm 72.79 \mathrm{~g}$ vs $811.8 \pm 86.07 \mathrm{~g}, p=0.001$ ), and even cervical clamp used in the ward, the blood loss within 30 or $30 \sim 60$ min was also different between two groups $(42.8 \pm 6.60 \mathrm{~g}$ vs $126.3 \pm$ $86.97 \mathrm{~g}, p=0.007 ; 10.4 \pm 1.96 \mathrm{~g}$ vs $21.88 \pm 2.30 \mathrm{~g}, P=0.000$, respectively), but the mean hemoglobin and incidence of blood transfusion were also similar in both groups. The rate of uterotonic repeated usage ( $\leq 2$ or $\geq 3$ types/times) in clamp group was obviously lower than control group ( $81.8 \%$ vs $36,18.2 \%$ vs $64 \%, p=0.001)$, consequently, side effect secondary to uterotonics including water intoxication, nausea, vomiting or increased blood pressure etc. presented less in clamp group ( $18.2 \%$ vs $48.0 \%, p=0.031)$. In addition, none of clamp complications such as failure, infection, pain, bladder or cervix injury presented, and mean hospital stay was similar in both groups $(4.1 \pm 1.57 \mathrm{~d}$ vs $3.8 \pm 1.61 \mathrm{~d}, p=0.535)$. Although intrauterine Bakri balloon or UAE had been used, there was not statistically significant between clamp and control group ( $4.5 \%$ vs $12 \%$, $p=0.36 ; 4.5 \%$ vs $4.0 \%, p=0.93$, respectively), and no laparotomy in both groups (Table 2).

\section{Discussion}

Uterine atony accounted for 70 80\% of etiology in postpartum hemorrhage, and the incidence of uterine atony was continuously increasing $[12,13]$. In 2019, the rate of postpartum hemorrhage in West China Second Hospital of Sichuan University was about $6.0 \%$, and uterine atony was the leading cause. Currently, active management of the third stage of labor was recommended as a prevention to reduce postpartum hemorrhage such as oxytocin administration, uterine massage and umbilical cord traction [14-16]. Except for Oxytocin, almost 3 25\% of cases in $\mathrm{PPH}$ required another uterotonic including ergonovine, carbetocin, 15-methyl prostaglandin F2-a or misoprostol [17]. But some problems could not be overlooked, gestational hypertension, preeclampsia, heart disease, glaucoma, asthma and drug hypersensitivity were uterotonic contraindications, and drug life-time limits its repeated usage in a short time, uterotonics also brought side effect like nausea, vomiting, diarrhea, headache and increased blood pressure [8], a systematic review in 2015 even found no satisfactory evidence could suggest what kind of uterotonic was the most effective for uterine atony [18]. Two previous studies mentioned so-called clamp for fixing intrauterine balloon, or recommending Bilateral Cervix Apex Clamping (BCAC) procedure as a noninvasive therapy for severe postpartum hemorrhage $[11,19]$, both operations were completely different from bilateral-contralateral cervix clamp we proposed. The present study found this new technique could effectively reduce blood loss at third stage of labor or after vaginal/caesarean birth, and it was much safer than uterotonics. However, the bilateral-contralateral cervix clamp could not be recommended during caesarean section, because it was not a more rapid, immediate choice in comparison with surgical measures.

Maternal deaths caused by postpartum hemorrhage still varied in regions with different medical levels, compared with $31 \%$ of maternal deaths in Asia, $21 \%$ in Latin America, $34 \%$ in Africa were caused by postpartum hemorrhage, however, only $13 \%$ in developed countries such as the United States and 18\% in France [20, 21]. If uterotonics failed, intrauterine Bakri balloon and invasive management such as uterine artery intervention or laparotomy may be recommended as second-line therapy to treat refractory hemorrhage [22, 23]. It was reported that $86 \%$ of women who had balloon tamponade did not require further procedures, and the success rate of UAE was greater than $80 \%$, but UAE required rapid access to computed tomography and interventional radiologist, not 
Table 1 Maternal and pregnancy characteristics of the study groups

\begin{tabular}{|c|c|c|c|}
\hline Characteristics & $\begin{array}{l}\text { Clamp group } \\
(n=22)\end{array}$ & $\begin{array}{l}\text { Control group } \\
(n=25)\end{array}$ & $P$ value \\
\hline Age (year), mean (SD) & $31.0 \pm 3.62$ & $30.9 \pm 3.65$ & .907 \\
\hline BMI $\left(\mathrm{kg} / \mathrm{m}_{2}\right)$, mean (SD) & $22.5 \pm 1.66$ & $22.2 \pm 1.85$ & .600 \\
\hline Gravidity, n (\%) & & & .949 \\
\hline$\leq 2$ & $13(59.1 \%)$ & $15(60 \%)$ & \\
\hline$\geq 3$ & $9(40.9 \%)$ & $10(40 \%)$ & \\
\hline Parity, n (\%) & & & .753 \\
\hline$<2$ & $14(63.6 \%)$ & $17(68 \%)$ & \\
\hline$\geq 2$ & $8(36.4 \%)$ & $8(32 \%)$ & \\
\hline Pregnancy, n (\%) & & & .553 \\
\hline Single & $18(81.8 \%)$ & $22(88 \%)$ & \\
\hline Twins & $4(18.2 \%)$ & $3(12 \%)$ & \\
\hline Delivery method, n (\%) & & & .706 \\
\hline Cesarean delivery & $10(45.5 \%)$ & $10(40 \%)$ & \\
\hline Vaginal delivery & $12(54.5 \%)$ & $15(60 \%)$ & \\
\hline Scarred uterus, n (\%) & $8(36.4 \%)$ & $6(24 \%)$ & .355 \\
\hline ART n (\%) & $7(31.8 \%)$ & $5(20 \%)$ & .354 \\
\hline PROM n (\%) & $7(31.8 \%)$ & $8(32 \%)$ & .989 \\
\hline ICP n (\%) & $2(9.1 \%)$ & $3(12 \%)$ & .746 \\
\hline Uterotonic contraindications, n (\%) & $12(54.5 \%)$ & $10(40 \%)$ & .319 \\
\hline Abnormal placenta, $\mathrm{n}(\%)$ & & & .749 \\
\hline Placental adhesion & $6(27.3 \%)$ & $8(32 \%)$ & \\
\hline Low placenta & $2(9.1 \%)$ & $1(4 \%)$ & \\
\hline Placenta previa & $2(9.1 \%)$ & $2(8 \%)$ & \\
\hline \multicolumn{4}{|l|}{ Surgical measures in groups, $\mathrm{n}(\%)$} \\
\hline Repair of lower uterus & $6(27.3 \%)$ & $6(24 \%)$ & 651 \\
\hline Uterine binding & $6(27.3 \%)$ & $7(28 \%)$ & .956 \\
\hline Uterine cavity packing & $8(37.4 \%)$ & $3(12 \%)$ & .105 \\
\hline Uterine suture & $1(4.5 \%)$ & $6(24 \%)$ & $.049^{\mathrm{a}}$ \\
\hline Ligation of uterine artery & 0 & $3(12 \%)$ & $.046^{\mathrm{a}}$ \\
\hline Newborn weight (g), mean (SD) & $2832 \pm 1067$ & $3060 \pm 1039$ & .706 \\
\hline
\end{tabular}

Abbreviations: BMI Body mass index, ART Assisted reproductive technology, PROM Premature rupture of membranes, ICP Intrahepatic cholestasis of pregnancy, SD Standard deviation, CS Caesarean section; Uterotonic contraindications such as Gestational hypertension, Preeclampsia, Heart disease, Glaucoma, Bronchial asthma etc. ${ }^{a}$ Denotes significant values if $p<0.05$

available to all hospitals [24, 25]. Lack of uterotonics, Bakri balloon and UAE, maternal women in low income areas would be in high risk of hysterectomy and death. As for bilateral-contralateral cervix clamp, only two sponge forceps required for hospitals, also no extra charge for patients, and trained obstetrician/midwife could accomplish in $5 \mathrm{~min}$, so this new technique could be another uteruspreserving management at basic-level hospital. Because no extra nursing or hospital stay required, there was also no increased burden for patient.

Even the present study was a retrospective cohort study, several ways increased its strengths. First of all, both inclusion and exclusion criteria were strictly made, three experienced midwives or obstetricians together improve accuracy of blood loss, and quantitative analysis helped directly confirm its efficacy. Then comparison of side effect, complications and cost indirectly explained its advantage. The limitations of this study included a small sample size, lacking randomization and long-term follow up. Most of all, present study couldn't prove it work in severe PPH $(\geq 1000 \mathrm{ml})$, or reducing incidence of intrauterine Bakri balloon, UAE or laparotomy. The future study will make perspective randomized controlled trial (RCT) and increase samples. 
Table 2 Comparison of treatment between clamp and control groups

\begin{tabular}{|c|c|c|c|}
\hline & $\begin{array}{l}\text { Clamp group } \\
(n=22)\end{array}$ & $\begin{array}{l}\text { Control group } \\
(n=25)\end{array}$ & $P$ value \\
\hline Bleeding in labor $(n=27)$ & $(n=12)$ & $(n=15)$ & \\
\hline Intrapartum blood loss (g), mean (SD) & $656.2 \pm 72.79$ & $811.8 \pm 86.07$ & $.001^{\mathrm{a}}$ \\
\hline Bleeding in the ward $(n=20)$ & $(n=10)$ & $(n=10)$ & \\
\hline Blood loss in 30 min (g), mean (SD) & $42.8 \pm 6.60$ & $126.3 \pm 86.97$ & $.007^{\mathrm{a}}$ \\
\hline Blood loss in 30 60 min (g), mean (SD) & $10.4 \pm 1.96$ & $21.88 \pm 2.30$ & $.000^{\mathrm{a}}$ \\
\hline \multicolumn{4}{|l|}{ Hemoglobin (g/L),mean (SD) } \\
\hline Preoperative $\mathrm{Hb}$ & $119 \pm 4.10$ & $121.4 \pm 4.19$ & .058 \\
\hline Postoperative Hb & $96.9 \pm 8.33$ & $96.1 \pm 7.39$ & .718 \\
\hline Blood transfusion, $\mathrm{n}(\%)$ & $2(9.1 \%)$ & $3(12 \%)$ & .746 \\
\hline Repeated usage of uterotonic, $n(\%)$ & & & $.001^{\mathrm{a}}$ \\
\hline$\leq 2$ (type/time) & $18(81.8 \%)$ & $9(36 \%)$ & \\
\hline$\geq 3$ (type/time) & $4(18.2 \%)$ & $16(64 \%)$ & \\
\hline Uterotonic side effect, n(\%) & $4(18.2 \%)$ & $12(48 \%)$ & $.031^{\mathrm{a}}$ \\
\hline Clamp complications, n(\%) & 0 & - & \\
\hline \multicolumn{4}{|l|}{ Surgical procedures, $\mathrm{n}(\%)$} \\
\hline Intrauterine Bakri balloon & $1(4.5 \%)$ & $3(12 \%)$ & $.36^{\mathrm{a}}$ \\
\hline Urgent UAE & $1(4.5 \%)$ & $1(4.0 \%)$ & $.93^{\mathrm{a}}$ \\
\hline Laparotomy & 0 & 0 & - \\
\hline Hospital stay (days), mean (SD) & $4.1 \pm 1.57$ & $3.8 \pm 1.61$ & .535 \\
\hline
\end{tabular}

Abbreviations: Hb Hemoglobin, UAE Uterine artery embolization, SD Standard deviation; ${ }^{a}$ Denotes significant values if $p<0.05$

\section{Conclusions}

The bilateral-contralateral cervix clamp was simple, effective, safe, low-cost, which could be a complementary treatment for PPH secondary to uterine atony at third stage of labor or after delivery, especially appropriate for pregnant women with uterotonic contraindications and hospital in poor conditions.

\section{Abbreviations}

PPH: Postpartum hemorrhage; UAE: Uterine artery embolization; CS: Caesarean section; BMI: Body mass index; ART: Assisted reproductive technology; PROM: Premature rupture of membranes; ICP: Intrahepatic cholestasis of pregnancy; SD: Standard deviation

\section{Acknowledgements}

Authors want to thank all the pregnant women for their involvement to this study.

\section{Authors' contributions}

Design of the work: YH. Data collection: TL and YX. Data analysis and interpretation: QZ. Drafting and critical revision of the article: QZ and YH. Final approval of the version to be published: QZ, TL, YX and YH. All the authors indicated that have read and approved the final version of the manuscript.

\section{Funding}

Professor $\mathrm{YH}$ is responsible for all the funding below, thanks for her active support specially. The design of this work was supported by Basic Applied Research in Sichuan Province, China (grant number 2019YJ0086), collection supported by Chengdu Science and Technology Innovation R\&D Project (grant number 2019-YF05-00448-SN), data analysis and interpretation in writing supported by Hospital Clinical Research Fund Project in West China
Second University Hospital, Sichuan University, Chengdu, China (grant number KL024).

\section{Availability of data and materials}

The data of study are not publicly available due to ethical and legal restrictions. However, upon request, data may be available from Institutional Review Board of West China Second Hospital of Sichuan University.

\section{Ethics approval and consent to participate}

The current study was reviewed and qualified as an exemption by the Institutional Review Board of West China Second Hospital of Sichuan University, Chengdu, China (number 2020068). Trial registration: 2020068. Registered March 1 2020, http://www.motherchildren.com. All study participants provided an informed written consent included the records of hospital.

\section{Consent for publication}

Consent to publish clinical details of the mothers and babies included in the current study was obtained from the mothers.

\section{Competing interests}

The authors declare that they have no competing interests.

Received: 30 September 2020 Accepted: 22 December 2020

Published online: 13 January 2021

\section{References}

1. Souza JP, Gülmezoglu AM, Vogel J, Carroli G, Lumbiganon P, Qureshi Z, et al. Moving beyond essential interventions for reduction of maternal mortality (the WHO multicountry survey on Maternal and newborn health): a cross-sectional study. Lancet. 2013;381(9879):1747-55. https://doi.org/10. 1016/S0140-6736(13)60686-8.

2. Magann EF, Evans S, Hutchinson M, Collins R, Howard BC, Morrison JC. Postpartum hemorrhage after vaginal birth: an analysis of risk factors. South Med J. 2005;98(4):419-22. https://doi.org/10.1097/01.SMJ.0000152760.34443.86. 
3. Say L, Chou D, Gemmill A, Tunçalp Ö, Moller AB, Daniels J, et al. Global causes of maternal death: a WHO systematic analysis. Lancet Glob Health. 2014;2(6):e323-33. https://doi.org/10.1016/S2214-109X(14)70227-X

4. GBD 2015 Maternal Mortality Collaborators. Global, regional, and national levels of maternal mortality, 1990-2015: a systematic analysis for the global burden of disease study 2015. Lancet. 2016;388(10053):1775-812. https://doi. org/10.1016/S0140-6736(16)31470-2

5. China Maternal and Child Health Surveillance Office. National Maternal and Child Health Surveillance. http://www.mchscn.org/admin/xiazai/tongxun/ The first issue of the National Maternal and Child Health Monitoring and Annual Report 2020.pdf [Accessed 7 Aug 2020].

6. WHO recommendations: uterotonics for the prevention of postpartum haemorrhage. Geneva: World Health Organization; 2018. Licence: CC BY-NC-SA 3.0 IGO. https://mww.who.int/reproductivehealth/help-health-workers-prevent-pph/en/.

7. Gallos ID, et al. Uterotonic agents for preventing postpartum haemorrhage: a network meta-analysis. Cochrane Database Syst Rev. 2018;2018:1. https:// doi.org/10.1002/14651858.CD011689.pub3.

8. Evensen A, Anderson JM, Fontaine P. Postpartum hemorrhage: prevention and treatment. Am Fam Phys. 2017;95(7):442-9.

9. Dombrowski, Michael, and M. Paidas. Obstetrical Management of Postpartum Hemorrhage. Transfusion Management of the Obstetrical Patient. 2018. doi:https://doi.org/10.1007/978-3-319-77140-3_1.

10. Lale S, Doris C, Alison G, et al. Global causes of maternal death: a WHO systematic analysis. Lancet Glob Health. 2014. https://doi.org/10.1016/S2214109X(14)70227-X.

11. Jiang L. Bilateral cervix apex clamping procedure can be used as a new noninvasive second line therapy for postpartum hemorrhage. Eur J Obstet Gynecol Reprod Biol. 2019;241:66. https://doi.org/10.1016/j.ejogrb.2019.08.005

12. Bateman BT, Berman MF, Riley LE, et al. The epidemiology of postpartum hemorrhage in a large, Nationwide sample of deliveries. Obstet Anesth Dig. 2011;31(2):89. https://doi.org/10.1097/01.aoa.0000397118.20085.45.

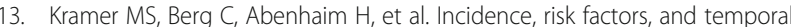
trends in severe postpartum hemorrhage [J]. Am J Obstet Gynecol. 2013; 209(5):449.e1-7. https://doi.org/10.1016/j.ajog.2013.07.007.

14. Guidelines for Oxytocin Administration after Birth: AWHONN Practice Brief Number 2. J Obstet Gynecol Neonatal Nurs Jognn 44.1(2015):161-163.doi: https://doi.org/10.1111/1552-6909.12528.

15. World Health Organization. Department of Reproductive Health and Research. WHO recommendations for the prevention and treatment of postpartum haemorrhage.2012. doi:https://doi.org/10.1093/bja/aeu448.

16. Begley $\mathrm{CM}$, et al. Active versus expectant management for women in the third stage of labour. Cochrane Database Syst Rev. 2015;65(7):1399-400. https://doi.org/10.1002/14651858.CD007412.pub2.

17. Bateman BT, Tsen LC, Liu J, et al. Patterns of second-line Uterotonic use in a large sample of hospitalizations for childbirth in the United States. Surv Anesthesiol. 2015;59(4):177-8. https://doi.org/10.1097/01.sa.0000466253.84962.df.

18. Likis FE, Sathe NA, Morgans AK, Hartmann KE, Young JL, Carlson-Bremer D, Schorn M, Surawicz T, Andrews J. Management of postpartum hemorrhage. Rockville: Agency for Healthcare Research and Quality (AHRQ). Comparative Effectiveness Review No 151; 2015.

19. Woiski MD, et al. Guideline-based development of quality indicators for prevention and management of postpartum hemorrhage. Acta Obstet Gynecol Scand. 2015;94(10):1118-27. https://doi.org/10.1111/aogs.12718.

20. Hogan MC, Foreman KJ, Naghavi M, et al. Maternal mortality for 181 countries, 1980-2008: a systematic analysis of progress towards millennium development goal 5. Lancet. 2010;375(9726):1609-23. https://doi.org/10. 1016/S0140-6736(10)60518-1.

21. Saucedo M, Deneux-Tharaux C, et al. Ten years of confidential inquiries into maternal deaths in France, 1998-2007. Obstet Gynecol. 2013;122(4):752-60. https://doi.org/10.1097/AOG.0b013e31829fc38c.

22. Sentilhes L, Vayssière C, Deneux-Tharaux C, et al. Postpartum hemorrhage: guidelines for clinical practice from the French College of Gynaecologists and Obstetricians (CNGOF) in collaboration with the French Society of Anesthesiology and Intensive Care (SFAR). Eur J Obstet Gynecol. 2015;198. https://doi.org/10.1016/j.ejogrb.2015.12.012..

23. Laas $E$, Bui $C$, Popowski $T$, et al. Trends in the rate of invasive procedures after the addition of the intrauterine tamponade test to a protocol for management of severe postpartum hemorrhage. Am J Obstet Gynecol. 2012;207(4):281.e1-7. https://doi.org/10.1016/j.ajog.2012.08.028.

24. Revert M, Cottenet J, Raynal P, Cibot E, Quantin C, Rozenberg P. Intrauterine balloon tamponade for management of severe postpartum haemorrhage in a perinatal network: a prospective cohort study. BJOG Int J Obstet Gynaecol 2017;124(8):1255-62. https://doi.org/10.1111/1471-0528.14382.

25. Zwart JJ, Dijk PD, Roosmalen JV. Peripartum hysterectomy and arterial embolization for major obstetric hemorrhage: a 2-year nationwide cohort study in the Netherlands. Am J Obstet Gynecol. 2010;202(2):150.e1-7. https://doi.org/10.1016/j.ajog.2009.09.003.

\section{Publisher's Note}

Springer Nature remains neutral with regard to jurisdictional claims in published maps and institutional affiliations.
Ready to submit your research? Choose BMC and benefit from:

- fast, convenient online submission

- thorough peer review by experienced researchers in your field

- rapid publication on acceptance

- support for research data, including large and complex data types

- gold Open Access which fosters wider collaboration and increased citations

- maximum visibility for your research: over $100 \mathrm{M}$ website views per year

At BMC, research is always in progress.

Learn more biomedcentral.com/submissions 